\title{
Влияние интеллектуального капитала и распространения знаний на динамику производительности труда в условиях региональных ресурсных ограничений ${ }^{1}$
}

\author{
Мария Мархайчук', Наталья Коваленко², Андрей Чекунов ${ }^{3 *}$, \\ Наталья Брюхина ${ }^{4}$ \\ ${ }^{1}$ Владимирский государственный университет имени Александра Григорьевича и Николая Гри- \\ горьевича Столетовых», г. Владимир, Россия \\ ${ }^{2}$ Южно-российский институт управления Российской академии народного хозяйства и государст- \\ венной службы при Президенте Российской Федерации, г. Ростов-на-Дону, Россия \\ ${ }^{3}$ Ростовский областной союз потребительских обществ, г. Ростов-на-Дону, Россия \\ ${ }^{4}$ Луганский национальный университет имени Владимира Даля, г. Алчевск, Луганская Народная \\ Республика
}

Информация о статье

Поступила в редакцию:

27.11.2020

Принята

к опубликованию:

18.12.2020

УДК 331.101 .6

JEL J24, R1

\section{Ключевые слова:}

производительность труда, региональный интеллектуальный капитал, диффузия знаний, информационная экономика, расширенное воспроизводство, общество знаний, ресурсный подход, ресурсные ограничения

\section{Keywords:}

labor productivity, regional intellectual capital, knowledge diffusion, information economy, extended reproduction, knowledge society, resource approach, resource constraints

\begin{abstract}
Аннотация
В статье анализируется влияние интеллектуального капитала и определяюших его факторов на динамику производительности труда в условиях региональных ресурсных ограничений. В настоящее время информаччя является ключевым экономическим ресурсом, который наряду с трудом, капиталом и природными ресурсами, определяет совокупную эффективность производства и экономическую динамику. $B$ условиях ограниченности инвестиционных ресурсов наиболее перспективным речением задачи повышения производительности труда должно стать увеличение вклада трудовых ресурсов в формируемую добавленную стоимость за счет использования преимуществ информационной экономики.
\end{abstract}

The Impact of Intellectual Capital and the Spread of Knowledge on the Labor Productivity Dynamics in the Context of the Regional Resource Constraints

Maria Markhaichuk, Natalya Kovalenko, Andrey Chekunov, Natalia Brjuhina

\begin{abstract}
The paper is devoted to substantiating the influence of the regional intellectual capital on the labor productivity dynamics at the enterprises of the non-resource sector of the Russian Federation regions. With the public knowledge transformation and the economy informatization, standard estimates of labor productivity and factors affecting its growth are changing. The role of the labor factor is changing, and the relationship between the growth of labor productivity and the development of human capital, namely its intellectual component, is being strengthened.

The analysis of the empirical studies has shown the positive impact of the regional intellectual capital on the economic dynamics and the innovations performance. In the information
\end{abstract}

\footnotetext{
${ }^{1}$ Исследование выполнено при финансовой поддержке РФФИ в рамках научного проекта № 20-010-00877

* Автор для связи: chekunovandrey61@mail.ru

DOI: https://dx.doi.org/10.24866/2311-2271/2020-4/51-60
} 
economy, the knowledge invested by a person in the product of his labor remains with him and can be used repeatedly, unlike the classical model of the industrial economy, where there is a constant alienation of a person from the results of his work. The information with a market value, that can generate profits or increase the market value of assets, is a source of information resources for the regional economy development.

The intellectualization of the society and the digitalization of the economy require long-term planning, the development of the appropriate competencies and the transformation acceleration. The main focus of the regional development programs should be the adaptation and development of the labor force intellectual capital, which will give a new impetus to the digitalization and governance reforms. The results of the study can be practical in the development of proposals to adjust the regional development strategies.

The reported investigation was funded by RFBR, project number 20-010-00877.

Современный этап общественного развития характеризуется переходом к новой форме постиндустриального общества и новому типу мировой экономики, где конкретные личностные знания формируются в результате инновационного процесса синтеза знаний и творчества посредством новых информационных технологий. Глобализация, становление наукоемкой экономики и переход к инновационно-цифровой экономике обуславливают необходимость оценки интеллектуальной составляющей человеческого капитала и поиск драйверов роста высокотехнологичного и высокоэффективного производства для обеспечения конкурентоспособности территорий. В результате концептуальных и структурных преобразований экономических действий произошел переход к научно обоснованной деятельности. Эффективность организации инновационного процесса и результат инноваций связаны с ростом экономики. Согласно единой теории роста, переход от стагнации к росту является неизбежным результатом процесса развития, который невозможен без инноваций. Флагманами экономики нового типа становятся высокотехнологичные отрасли, основная часть которой связана с воспроизводством новых знаний, преобладанием интеллектуального труда, полномасштабным производством интеллектуальной продукции. В связи с этим ускоренными темпами идет развитие сферы знаний и информации, цифровизация экономики трансформирует структуру занятости. Нематериальные активы предприятий превалируют по сравнению с физическими активами, акцентируя внимание на значимости интеллектуальной собственности. Наряду с традиционными субъектами инновационной деятельности увеличивается количество инновационно активных предприятий. Переход к инновационно-цифровой экономике невозможен без роста эффективности воспроизводства интеллектуального капитала.

Перед каждым регионом стоит задача: в условиях ресурсных ограничений обеспечить рост производительности труда и развитие человеческого капитала. Человеческий капитал растет кумулятивно в течение длительного периода времени. Когда общество концентрируется на развитии человеческого капитала и, в свою очередь, повышении производительности труда, долгосрочный экономический рост будет устойчивым. Экономический вклад в образование, здравоохранение и производительность труда влияет на будущие поколения, гарантируя, что они будут более инновационными и эффективными, чем нынешнее поколение. Повышение эффективности труда является прямым результатом более высокого качества рабочей силы, создаваемой за счет развития человеческого капитала. Рост производительности труда обеспечивает дополнительные конкурентные преимущества для развития экономики регионов.

Анализ последних исследований отечественных и зарубежных авторов свидетельствует о том, что в условиях трансформации общественного знания и информатизации экономики изменяются стандартные оценки производительности труда и влияющие на ее рост факторы. Ученые отмечают, что меняется роль фактора труда, акцентируя внимание на взаимосвязи роста производительности 
труда и развития человеческого капитала, а именно интеллектуальной его составляющей. В более ранних исследованиях практически не рассматривалась взаимосвязь между интеллектуальным капиталом и производительностью труда.

Целью данного исследования является теоретическое обоснование влияния интеллектуального капитала на динамику производительности труда посредством распространения знаний и развития региональных инновационных возможностей в условиях ресурсных ограничений.

Человеческое развитие, по мнению Программы развития Организации Объединенных Наций (далее - ПРООН), - это развитие людей через создание человеческих ресурсов для трансляции преимуществ развития в их жизни через активное участие в процессах, которые влияют на их жизнь и формируют её [1]. При этом ПРООН отмечает, что национальное развитие должно определяться не только доходом на душу населения, но и достижениями в области здравоохранения и образования. В работе N. Lind [2] делается вывод, что развитие человека отражается, в частности, на росте производительности и образовании. При этом T. Suri с соавторами констатировали наличие взаимосвязи между человеческим развитием и экономическим ростом [3]. Однако человеческое развитие в целом по стране и между ее отдельными регионами может существенно отличаться. Соответственно, и уровень развития регионального интеллектуального капитала между регионами может иметь сильные различия.

Концепция интеллектуального капитала в современных условиях выступает критерием социально-экономической эффективности регионального и государственного развития. Эмпирические результаты исследования регионального интеллектуального капитала G. Schiuma показали положительную связь между владением интеллектуальным капиталом и созданием стоимости [4]. Y. Lapygin и Р. Makarov указывают на возрастающую значимость интеллектуального капитала как фактора экономического роста [5].

B исследовании C. Liu установлена положительная корреляция между peгиональным интеллектуальным капиталом и развитием региональной экономики [6]. A. Pöyhönen, A. Smedlund в рамках теоретической модели динамики создания интеллектуального капитала в региональных кластерах и межорганизационных сетях рассматривают организации как системы знаний [7]. J. Ren пришел к выводу, что интеллектуальный капитал развил основную поддержку страны и региона в экономике знаний [8].

Интеллектуальная составляющая человеческого капитала региона определяет эффективность его инновационной деятельности [9]. S. Dezhong сделал вывод, что интеграция интеллектуального капитала имеет важное значение для региональной инновационной системы, осуществляющей технологические инновации, и повышение эффективности интеграции интеллектуального капитала целесообразно для роста региональных инновационных возможностей [10].

Региональная политика приобретает все большее значение в стимулировании инноваций в бизнесе из-за двойного политического сдвига. Во-первых, во многих странах процессы передачи полномочий и децентрализации, а также растущие требования к политической подотчетности и мониторингу результатов привели к многоуровневому политическому подходу к инновациям, что повысило роль регионов. Вовторых, мы стали свидетелями смены парадигмы в самой политике регионального развития. После провала различных региональных стратегий, нацеленных на экономически маргинализированные районы, в 1990-е гг. появились новые рамки, нацеленные на создание эндогенного роста в каждой территории на основе ее уникальных местных активов, возможностей и потенциалов, избегая “универсального" подхода. Поэтому регионы все чаще призываются к тому, чтобы стать фасилитаторами инновационных 
систем, а не субсидиантами, играя роль управляющих взаимодействием в рамках сетей государственно-частного партнерства. Директивные органы должны поощрять управление знаниями между фирмами и внутри них, обеспечивая взаимодополняемость между политикой и инструментами на различных уровнях управления.

Однако стоит отметить, что регион - это замкнутая система, которая обладает ограниченными ресурсами. Способность использования ресурсов ограничивается технологиями и капиталом. Согласно Н. Blair и P. Olpadwala peсурсные ограничения являются барьерами для развития (физические, человеческие и (или) финансовые), возникающие из-за простой недоступности необходимых ресурсов [11]. Несогласованность политики в области производства, технологий и ресурсов (упущенная возможность создания и получения стоимости за счет взаимодополняемости, обусловленной ресурсами) со временем определяется как основной сдерживающий фактор для стран как на начальном, так и на более прогрессивном этапах развития производства [12]. W.M. Getz предположил, что темпы роста населения зависят от наличия ресурсов на душу населения [13].

Повышение технологического уровня, рост численности населения и изменение его состава ускорили технологический прогресс, что в конечном итоге повысило значимость человеческого капитала в производственном процессе. В настоящее время в связи с демографическим старением населения, нехваткой инженерных кадров, миграцией высококвалифицированных рабочих за рубеж существует проблема воспроизводства интеллектуального капитала. Несмотря на то, что сегодня предложение высококвалифицированных работников на рынке труда увеличилось и продолжает расти, растет и уровень образования населения (растет число людей, получающих высшее образование, защищающих магистерские и докторские диссертации), при этом наблюдается нехватка высококвалифицированных рабочих и специалистов.

O.L. Taran с группой соавторов рассматривают совокупный экономический потенциал региона как совокупность условий, ресурсов и факторов, обеспечивающих процесс воспроизводства в зависимости от уровня их интернализации и утилизации [14]. Yu.A. Drozdova указывает на особую значимость ресурсного подхода в рамках исследования перспектив развития территориальных общностей [15]. P. Makarov считает интеллектуальный капитал частью системы общественного воспроизводства [16].

Интеллектуальный капитал в процессе распространения знаний в условиях ресурсных ограничений влияет на производительность труда. Производительность является ключевым фактором, способствующим повышению уровня жизни общества. M.D. Pandey и его соавторы пришли к выводу, что ключевые факторы, определяющие производительность, - это: физический капитал (запас производственных машин, установок и оборудования, используемых рабочими для производства), человеческий капитал (относится к знаниям и навыкам, которые рабочие приобретают благодаря образованию, обучению и опыту) и технологические знания (относятся к пониманию оптимизированных способов производства товаров и услуг для определенной комбинации капитала и рабочей силы) [17]. Одним из наиболее важных ресурсов, на которые опираются организации, является человеческий капитал, поскольку он помогает организациям инновационно реагировать на изменения окружающей среды. Кроме того, человеческий капитал способен повышать эффективность и результативность деятельности организаций, обеспечивая конкурентные преимущества.

A. Javaid определяет производительность как участие людей в генерации дохода, т.е. люди должны в полной мере участвовать в генерации дохода, а правительство разрабатывать более эффективные социальные программы для своих 
людей [18]. Исследования ученых свидетельствуют о том, что с развитием технологий происходит трансформация факторов, влияющих на рост производительности труда. Интеллектуализация и информатизация экономических процессов развитых стран свидетельствует об усилении роли рабочей силы в процессе производства и создания прибавочного продукта. Этот процесс основан не только на необходимости привлечения квалифицированных рабочих для обслуживания модернизированных производств. Основной акцент делается на способности работника посредством своего интеллекта производить специфический продукт - интеллектуальный. Посредством приобретения новых знаний, умений и навыков работник осваивает модернизированные производства, участвуя в создании прибавочного продукта.

Интеллектуализация экономики обуславливает необходимость расширенного воспроизводства новейших умений, знаний, навыков и способностей работников, которые будут способствовать формированию воспроизводственных факторов производства, которые учитывают инновационные перемены, в том числе, перемену труда [19]. Изменяя производственные и потребительские предпочтения, развитие технологий заложило основу для формирования экономики, основанной на знаниях. В экономике знаний продукты и услуги, основанные на интеллектуальной экспертизе, продвигают технические и научные области, стимулируя инновации в экономике в целом.

Термин «общество знаний» описывает общество, в котором генерация, распространение и эксплуатация знаний играют доминирующую роль в создании общественного благосостояния [20]. Развитие обществ знаний связано с основными преобразованиями в структуре экономической деятельности, когда знания являются двигателем большей части динамики экономической активности и источником значительного роста добавленной экономической стоимости. G. Japeе полагает, что общество знаний - это форма общества, в которой его члены постоянно изучают идеи [21].

S. Novikov в качестве атрибутивных признаков личности в отношении формирования общества выделяет постматериализм и стремление к творческой деятельности, обусловленной внутренним неэкономическим интересом и направленной на поиск новых идей [22]. Отличительной особенностью общества знаний является то, что оно организует приобретение, обеспечение, использование и распространение знаний и позволяет учреждениям и гражданам получать доступ к системам, основанным на знаниях.

Функционирование организаций в условиях неопределенности, изменений и нестабильности приводит к возникновению непредвиденных рисков. Тенденции, появившиеся в результате глобализации, формируют необходимость быстрой адаптации организаций к произошедшим трансформациям. Ключевым фактором для организаций в этих условиях становится интеллектуальный и нематериальный капитал, иными словами - знания. Усиливая ключевые компетенции фирмы, знания обеспечивают необходимые ресурсы для нововведений и поддержания конкурентных преимуществ. Концепция знаний является основным фактором, позволяющим организациям выжить в динамичной и конкурентной среде. Создание знаний, обмен этими знаниями между организационными подразделениями и воплощение этих знаний в новых технологиях и продуктах необходимо для поддержания конкурентного преимущества.

В условиях современного технологического уклада жизненно важным стал еще один фактор производства - это информация. Информация включает в себя факты и цифры о рынках и конкуренции, которые концентрируются в интернетпространстве и доступны в любое время. В условиях тотальной компьютериза- 
ции бизнес не может конкурировать без информации о рынках, финансовых условиях и других важных составляющих ведения бизнеса. Несмотря на то, что информация относится к факторам производства, она имеет ряд существенных отличий от других производственных факторов. Эти различия предопределяют необходимость переоценки способов группировки производственных факторов. В качестве основных свойств, которыми обладает информация, и которые используются в процессе распространения знаний можно выделить ее расширяемость, сжатие, замещение, переносимость, диффузию и доступность для коллективного использования. При распространении знаний информация расширяется и генерируется, предельно допустимые возможности этого процесса ограничены возможностями пользователей по анализу, хранению и извлечению информации. Использование телекоммуникационных технологий при передаче информации позволяет сократить время на принятие управленческих решений.

В настоящее время, учитывая повышенную роль информации как фактора производства и результата производственной деятельности, основной тенденцией развития любой страны является эффективное построение информационной (цифровой) экономики.

B. Babaev с соавторами подчеркивают необходимость государственного регулирования, направленного на принятие защитных мер для защиты высокотехнологичных отраслей с возрастающей отдачей, развития информационных и коммуникационных технологий для решения проблемы перехода к новому типу общественного воспроизводства - промышленно-информационное общество [23].

На современном этапе развития современных предприятий основным фактором формирования конкурентных преимуществ предприятия на рынке и повышения его конкурентоспособности является информатизация всех бизнеспроцессов. R. Rey пришел к заключению, что для эффективного решения задач новой информационной экономики компании организуются вокруг внутрифирменных сетей, обращаются к информационным технологиям и планируют свои стратегии в условиях глобальной конкуренции [24]. В условиях информационной экономики предприятиям необходима стратегия развития, учитывающая особенности мировых изменений в сферах производства, маркетинга, управления и т. д.

Знания производятся не только в новых местах, новых форматах и новых способах, но и распространяются в обществе благодаря действию информационных и коммуникационных технологий и распространению глобальных культур, образов и «брендов».

M. Rogers отмечает, что более широкое распространение знаний эффективно увеличивает общественный запас знаний, делая фирмы более продуктивными в создании новых знаний, что непосредственно влияет на экономический рост [25]. Ученый популяризировал теорию диффузии инноваций, которая объясняет причины и процесс распространения новых идей и технологий. При этом он рассматривает диффузию как процесс передачи нововведения во временном контексте между участниками социальной системы. В качестве элементов, влияющих на распространение новой идеи, ученый рассматривает инновацию, каналы связи, время и социальную систему, акцентируя внимание на зависимости этого процесса от человеческого капитала. Новшество должно широко применяться для того, чтобы самостоятельно поддерживаться.

D. Gallaud и A. Torre определили, что организация является первым способом передачи знаний, и что географическая близость может быть временной, особенно на начальных этапах процессов НИОКР [26].

R. Cowan и N. Jonard исследовали связь между сетевой архитектурой и диффузионной производительностью и обнаружили, что производительность 
системы демонстрирует явные свойства «маленького мира», в том, что устойчивый уровень среднего знания максимален, когда структура представляет собой маленький мир (то есть, когда большинство соединений локальные, но примерно 10 процентов из них на больших расстояниях) [27]. P. Guerrieri с соавторами построили модель, в которой экономический рост обусловлен также распространением технологий, что, в свою очередь, зависит от расстояния, а также от деловых услуг, производимых внутри страны и импортируемых [28]. Движущей силой экономического роста является сокращение информационных барьеров, способствующее созданию богатства.

Экономика знаний сосредоточилась на инновациях, творчестве и сетях в качестве движущих сил конкурентоспособности и экономического роста, что сместило перспективы развития с конкурентоспособности, основанной на материальных ценностях, на конкурентоспособность, основанную на знаниях, изменяя способ организации экономики и делая упор на появление нового типа капитала. В настоящее время имеет место повышение значимости нового производственного фактора - знаний и информации в обеспечении эффективности хозяйственной деятельности. Технология изменила работу и занятость, что делает работника, занятого знаниями, более вовлеченным в поддержание конкурентной среды. D. Yadransky и E. Chumak в качестве фактора, определяющего цену труда в информационной экономике, предлагают рассмотреть социальный спрос на конкретный товар (информацию) и субъективную оценку товара потребителем [29]. K. Sherringham и B. Unhelkar утверждают, что роли работников умственного труда трансформируются, поскольку ряд функций работника умственного труда предоставляется из облака как услуга, что предоставляет организации возможность быстрее реагировать на изменения [30].

Проведенное исследование позволяет говорить о трансформации факторов, влияющих на рост производительности труда. В условиях региональных ресурсных ограничений знания и информация становятся главным производственным фактором, обеспечивающим рост производительности труда и развитие региональных инновационных возможностей.

Изменения условий функционирования организаций (глобализация, нехватка ресурсов, демографические изменения и конкуренция) требуют от компаний принятия новых стратегий для обеспечения конкурентных преимуществ. Целью таких стратегий является получение инновационных результатов, отличающих их от других конкурентов во все более сложной деловой и экономической среде. Как показывают различные исследования, опираясь на ресурсноориентированные и эволюционные теории фирмы, посредством инноваций компании способны переосмыслить свои источники стратегического преимущества и освоить новые механизмы построения долговременной или устойчивой силы.

Следует отметить, что в связи с изменениями, произошедшими в мировой экономике в результате пандемии, вызванной короновирусной инфекцией нового типа, основным направлением становится адаптация и развитие интеллектуального капитала, что дает новый импульс цифровизации и реформам систем управления. Несмотря на то, что новые технологии и возможность доступа в интернет позволяют быстрее адаптироваться к новым условиям работы, для многих компаний удаленная работа в условиях пандемии создала определенные сложности для их компьютерной инфраструктуры и информационных систем. Интеллектуализация общества и диджитализация экономики требуют перспективного планирования, развития соответствующих компетенций и ускорения трансформации.

Успешные компании, внедряя инновации, используя новые технологии и навыки, обеспечивают развитие знаний своих сотрудников. Знания, являющиеся 
новым двигателем корпоративного развития, стали одним из ключевых факторов обеспечения конкурентного преимущества.

Выходя за рамки технологических инноваций, инновационные структуры должны быть «умными», решая не только пробелы в производительности труда, но и социальные проблемы, например, стимулируя социальный и экологический устойчивый рост. Этот более сбалансированный подход к инновациям также открывает новые возможности для регионов, которые не являются лидерами технологических преобразований, развивать свои существующие конкурентные преимущества. Фактически все секторы следует рассматривать как потенциально инновационные, уделяя больше внимания некоторым относительно новым областям. Наконец, такой подход к инновациям подчеркивает необходимость перехода к мезоуровневому анализу динамики инноваций. Действительно, в то время как в прошлом большинство инновационных структур принимали макроэкономическую перспективу, гораздо больше внимания следует уделять предпринимательству отдельных лиц и организаций и их взаимодействию в процессе генерирования, использования и распространения идей, продуктов и процессов. Сети знаний и бизнес-экосистемы, в которых работают фирмы, должны занимать центральное место в оценке эффективности инновационных систем и политики.

В условиях ограниченности инвестиционных ресурсов наиболее перспективным решением задачи повышения производительности труда должно стать увеличение вклада трудовых ресурсов в формируемую добавленную стоимость за счет использования преимуществ информационной экономики.

Важная роль интеллектуального капитала в инновационно-цифровой экономике порождает объективную необходимость углубленного изучения процессов его создания, формирования и применения, что позволит сделать правильный выбор ориентиров и направлений дальнейшего развития и приведет к созданию такой стратегии экономического развития, в основе которой лежит человек с накопленными знаниями, навыками и новаторскими идеями.

\section{Список источников / References}

1. United Nations Development Programme. Human Development Report 2016. Available at: https://gtmarket.ru/files/research/human-development-

index/Human_Development_Report_2016.pdf (accessed 10.09.2020).

2. Lind N.A. Development of the Human Development Index. Social Indicators Research, 2019, vol. 146, no. 3, pp. 409-423. DOI: 10.1007/s11205-019-02133-9.

3. Suri T., Boozer M.A., Ranis G., Stewart F. Paths to success: The relationship between human development and economic growth. World Development, 2011, vol. 39, no. 4, pp. 506-522. DOI: 10.1016/j.worlddev.2010.08.020.

4. Schiuma G., Lerro A., Carlucci D. The Knoware Tree and the Regional Intellectual Capital Index: An assessment within Italy. Journal of Intellectual Capital, 2008, vol. 9, no. 2, pp.283-300. DOI: 10.1108/14691930810870346.

5. Lapygin Y.N., Makarov P.Y. Strategic Alternatives of Regional Intellectual Capital Management. In: Popkova E. (eds) The Future of the Global Financial System: Downfall or Harmony. ISC 2018. Lecture Notes in Networks and Systems, vol 57. Springer, Cham, 2019. DOI: 10.1007/978-3-030-00102-5_55.

6. Liu C., Li X., Xu L. The Influence of Regional Intellectual Capital on Regional Economic Development: Evidence from Shandong Province. 2014 International Conference on Management of e-Commerce and e-Government, Shanghai, IEEE, 2014, pp. 280-284. DOI: 10.1109/icmecg.2014.64.

7. Pöyhönen A., Smedlund A. Assessing intellectual capital creation in regional clusters. Journal of Intellectual Capital, 2004, vol. 5, no. 3, pp. 351365. DOI:10.1108/14691930410550345. 
8. Ren J. Measure Research in Regional Intellectual Capital on the Basis of Multifactor Level Fuzzy Evaluation Method. 2008 Fifth International Conference on Fuzzy Systems and Knowledge Discovery, Vol. 3, Shanghai, IEEE, 2008, pp. 589-593. DOI: 10.1109/fskd.2008.591.

9. Loseva O., Fedotova M., Filimonova N. Methods for Measuring of Regional Intellectual Capital. Information, 2016, vol. 19, no. 6A, pp. 1771-1785.

10. Dezhong S. Regional Intellectual Capital Integration Performance Evaluation Based on Two-Phase Model. 2014 Sixth International Conference on Measuring Technology and Mechatronics Automation, Zhangjiajie, IEEE, 2014, pp. 467-471. DOI: 10.1109/ICMTMA.2014.115.

11. Blair H., Olpadwala P. Resource Constraints. In: Forestry in Development Planning, New York, Routledge, 2019, pp. 15-19. DOI: 10.4324/9780429044014-4.

12. Andreoni A. On manufacturing development under resources constraints. In M. Baranzini, C. Rotondi, \& R. Scazzieri (Eds.), Resources, Production and Structural Dynamics, Cambridge, Cambridge University Press, 2015, pp. 407-424. DOI: 10.1017/CBO9781139940948.023.

13. Getz W.M. Population dynamics: a per capita resource approach. Journal of Theoretical Biology, 1984, vol. 108, no. 4, pp. 623-643. DOI: 10.1016/s0022-5193(84)80082-x.

14. Taran O.L., Durdyeva D.A., Aslanov D.I., Bindasova N.A., Borlakova M.I. Assessment and Analysis of Resource Approach to Formation of Strategic Potential of Economy of the Region. International Review of Management and Marketing, 2016, vol. 6, no. S1, pp. 84-89.

15. Дроздова Ю.А. Ресурсный подход в исследовании территориальных общностей. Вестник Института социологии, 2019, том 10, №1, сс. 76-98. [Drozdova J.A. Resursnyi podkhod $\mathrm{v}$ issledovanii territorial'nykh obshchnostei [Resource approach in studying territorial communities]. Vestnik instituta sotziologii $=$ Bulletin of the Institute of Sociology, 2019, vol. 10., no. 1, pp. 76-98.] DOI: 10.19181/vis.2019.28.1.557.

16. Макаров П.Ю. Базовая модель механизма воспроизводства интеллектуального капитала региона. Вестник Томского государственного университета. Экономика, 2018, №41, cc. 41-54. [Makarov P.Yu. Bazovaya model' mekhanizma vosproizvodstva intellektual'nogo kapitala regiona [The framework of the regional intellectual capital economic reproduction mechanism]. Vestnik Tomskogo gosudarstvennogo universiteta. Ekonomika = Tomsk State University Journal of Economics, 2018, no. 41, pp. 41-54.] DOI: 10.17223/19988648/41/3.

17. Pandey M.D., Nathwani J.S., Lind N.C. The derivation and calibration of the life-quality index (LQI) from economic principles. Structural Safety, 2006, vol. 28, no. 4, pp. 341360. DOI: 10.1016/j.strusafe.2005.10.001.

18. Javaid A., Akbar A., Nawaz S. A Review on Human Development Index. Pakistan Journal of Humanities and Social Sciences, 2018, vol. 6, no. 3, pp. 357-369.

19. Покровский С.В. Совершенствование механизма функционирования интеллектуального капитала. Автореф. дисс. канд. экон. наук. Москва, 2009. 22 c. [Pokrovskii S.V. Sovershenstvovanie mekhanizma funktsionirovaniya intellektual'nogo kapitala. Avtoref. diss. kand. ekon. nauk. [Improving the mechanism of functioning of intellectual capital. Author's abstract Cand. Diss. (Econ.)]. Moscow, 2009, 22 p.]

20. Kastberg P. Knowledge Society. The International Encyclopedia of Strategic Communication, New York, John Wiley \& Sons Inc., 2018, pp. 1-5. DOI: 10.1002/9781119010722.iesc0097.

21. Japee G. Predicament of Knowledge Society: An Inquiry. International Journal of Interreligious and Intercultural Studies, 2019, vol. 2, no. 2, pp. 60-67. DOI: 10.32795/ijiis.vol2.iss2.2019.455.

22. Novikov S. The Goal Of Education In Knowledge Society. The European Proceedings of Social \& Behavioural Sciences EpSBS. EEIA 2019 - International Conference «Education Environment for the Information Age», Future Academy, Moscow, 2019, pp. 590-597. DOI: 10.15405/epsbs.2019.09.02.67.

23. Babaev B., Nikolaeva E., Babaev D., Borovkova N. Russia: Digital Economy or Industrial and Information Economy? In: Popkova E., Sergi B. (eds) Digital Economy: Complexi- 
ty and Variety vs. Rationality, ISC 2019. Lecture Notes in Networks and Systems, vol 87, Springer, Cham, 2020, pp. 332-341. DOI: 10.1007/978-3-030-29586-8_39.

24. Rey R. Social Networks in the Information Economy. Social Sciences. 2019, vol. 8, no. 2, pp. 62-66.

25. Rogers M. The diffusion of knowledge and economic growth. Economics. Thesis PhD. Canberra, 1997. 293 p. DOI: 10.25911/5d66648c2902e.

26. Gallaud D., Torre A. Geographical proximity and the diffusion of knowledge. In: Fuchs G., Shapira P. (eds) Rethinking Regional Innovation and Change. Economics of Science, Technology and Innovation, vol 30. New York, Springer, 2005, pp. 127-146. DOI: 10.1007/0-387-23002-5_7.

27. Cowan R., Jonard N. Network structure and the diffusion of knowledge. Journal of Economic Dynamics and Control, 2004, vol. 28, no. 8, pp. 1557-1575. DOI: 10.1016/j.jedc.2003.04.002.

28. Guerrieri P., Maggi B., Padoan P.C. Economic growth and diffusion of knowledge: the role of distance. CIDEI Working paper No. 70, 2006.

29. Yadransky D., Chumak E. Time as a resource of the information economy. Baltic Journal of Economic Studies, 2017, vol. 3, no. 5, pp. 462-468.

30. Sherringham K., Unhelkar B. Crafting and Shaping Knowledge Worker Services in the Information Economy. Springer, Palgrave Macmillan, Springer Nature Singapore, 2020, 566 p. DOI: 10.1007/978-981-15-1224-7.

\section{Сведения об авторах / About authors}

Мархайчук Мария Михайловна, кандидат экономических наук, доцент кафедры коммерции и гостеприимства, Владимирский государственный университет им. А.Г. и Н.Г. Столетовых. 600000 Россия, г. Владимир, улица Горького, 87. E-mail: m.marhaychuk@gmail.com

Maria M. Markhaichuk, Candidate of Economics, Associate Professor of the Department of Commerce and Hospitality, Vladimir State University named after Alexander and Nikolay Stoletovs. 600000, Russia, Vladimir, Street Gorky, 87. E-mail: m.marhaychuk@gmail.com

Коваленко Наталья Валерьевна, доктор экономических наук, профессор, профессор кафедры менеджмента, Южно-российский институт управления Российской академии народного хозяйства и государственной службы при Президенте Российской Федерации. 344002 Россия, г. Ростов-наДону, улица Пушкинская, 70/54. E-mail: sonatak96@gmail.com

Natalya V. Kovalenko, Doctor of Economics Sciences, Professor, Professor of the Department «Management» of South-Russian Institute of Management of the Russian Academy of National Economy and Public Administration under the President of the Russian Federation. 344002, Russia, Rostov-on-Don, Street Pushkinskaya, 70/54. E-mail: sonatak96@gmail.com

Чекунов Андрей Сергеевич, кандидат экономических наук, главный специалист-эксперт по развитию кооперации Ростовского областного союза потребительских обществ. 344002 Россия, г. Ростов-на-Дону, проспект Буденновский, 19a/55. E-mail: chekunovandrey61@ mail.ru

Andrey S. Chekunov, Candidate of Economics, Chief Expert on Development of Cooperation of Rostov Regional Union of Consumer Societies. 344002, Russia, Rostov-on-Don, Budennovsky Ave, 19a /55.

E-mail: chekunovandrey61@mail.ru

Брюхина Наталья Геннадьевна, ассистент кафедры экономики и управления факультета экономики и бизнеса, Луганский государственный университет им. Владимира Даля. 94200 Луганская Народная Республика, г. Алчевск, улица Фрунзе, 39. E-mail: anka033@yandex.ru

Natalia G. Brjuhina, Assistant of the Department of Economics and management of the faculty of Economics and business, Luhansk state University named after Vladimir Dal. 94200 Luhansk People's Republic, Alchevsk, Street Frunze, 39.E-mail: anka033@yandex.ru 